\title{
TRANSACTIONS SECTION
}

Preprint of Corresponding Pages From the Current Annual AIEE Transactions Volume

Any discussion of these papers will appear in the June 1943 Supplement to Electrical Engineering-Transactions Section

\section{Generation of Electric Charges by Moving Rubber-Tired Vehicles}

\section{S. S. MACKEOWN \\ MEMBER AIEE}

Synopsis: The current flowing to ground from an automobile, whose rear wheels were turning on a dynamometer, was measured. The magnitude of the constant current measured, in the order of microamperes, shows that the vehicle is electrically charged by conduction through the tires. The experimental results are consistent with the conception of a simple equivalent circuit. These results were checked by road tests. Calculation shows that the tires are usually conducting sufficiently to discharge a car in a short time after it has stopped moving

OMMON experience demonstrates that a rubber-tired vehicle in motion often accumulates a charge of electricity of sufficient magnitude to shock a person who touches the vehicle immediately after it comes to rest.

It is known that this electric charge is produced when the rubber tires contact pavement and then separate from it. This phenomenon has recently been studied by Beach, ${ }^{1}$ Cadwell, Handel, and Benson ${ }^{2}$ and by Liska and Hanson. ${ }^{3}$ These investigators studied the potentials developed and potential distributions around the tire. Most of our experiments were confined to the measurement of currents generated, rather than voltages.

Paper 43-50, recommended by the AIEE committe on basic sciences for presentation at the AIEE na tional technical meeting, New York, N. Y., January 25-29, 1943. Manuscript submitted May 22 1942; made available for printing December 21 , 1942.

3. S. MAckrown is professor of electrical engineering, California Institute of Technology, Pasadena, Calif., and Vrctor Wouk is with Westinghouse Electric and Manufacturing Company. East Pittsburgh, Pa.

The experimental work was financed by a grant from the American Petroleum Institute for a study of the production of electric charges in handling petroleum products, and the results described in this paper constitute a part of that program. The authors ack owledge the assistance of Harold Albin Pasadena, Calif., who made available the use of his dynamometer for this work.

\section{VICTOR WOUK \\ ASSOCIATE AIEE}

Theoretically there are two methods by which a vehicle can acquire a potential above ground caused by tire static. One method is by induction from the charges produced on the rubber tires. The other method is by the conduction of this charge through the rubber tires to the body of the vehicle. We have measured continuous currents, as high as four microamperes, flowing to a grounded conductor from a car, under normal driving conditions. This continuous current can be produced only by conduction through the tires. It is well known that any charges produced on the body of the car by induction from the charges on the tire, will produce only a momentary current when the vehicle is grounded, and cannot possibly maintain a steady current to ground.

Inductive effects due to the existence of charges on the surface of the tires can produce the distribution of charges on the body of the vehicle that is necessary to maintain the body at one potential. The potential, however, is determined entirely by current flowing through a resistance.

\section{Experimental Results}

It is difficult to make accurate measurements of currents generated by moving vehicles on the road. Accordingly, in the attempt to determine the currents generated, the first experiments were conducted on an engine-testing dynamometer stand. This device is essentially a large Prony brake. The rear wheels of the automobile rest on a large metal drum that is free to revolve at a rate corresponding to any desired road speed.
In making measurements of currents generated, the body of the car was grounded through a microammeter, the currents being large enough to come within the range of an ordinary instrument.

The rubber tires of a moving vehicle in contact with the pavement produce a difference of potential between the rubber and pavement, and a separation of electric charges occurs. The tire always acquires a negative charge. As the tires move from the contact position on the pavement, or on the dynamometer, the potential of the charges must increase. As the potential increases, the charges seek a path to ground. Our experiments have led us to the conclusion that two paths to ground are followed:

1. Directly across the tires to the wheel hub and the car body. and from the car body to ground through the ammeter.

2. Back along the surface of the tire to the grounded dynamometer, or, in the case of a moving vehicle, to the ground plane existing under the pavement

Thus, the equivalent circuit of a car on a dynamometer stand may be represented by Figure 1 . The current $I$ generated at the tire tread has two paths to ground:

1. To the wheel through the resistance of the tires, $R_{w}$, to the car body and througb the ammeter to ground

2. Back to ground across the surface of the tires, through a shunt resistance, $R_{\boldsymbol{l}}$.

Figure 2 is a typical curve showing the measured current plotted against speed of the rear wheels. This current flows from the body of the car to ground when the rear wheels revolve on the drum of the dynamometer. The data were taken with a 1941 Chevrolet having the standard 6:00-16 tires. Various pressures were used, and a wide range of tractive loads was applied. In general, we found only a small increase in current with a considerable increase in load and only a small increase in the current with a large decrease in tire pressure. These results indicate that the charges produced are not determined primarily by the amount of 

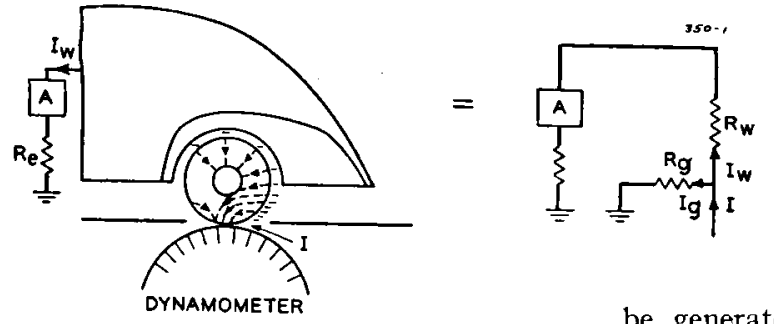

Figure 1. Equivalent circuit of a car on a dynamometer stand

friction, but rather by the speed and separation of contact.

The curve of Figure 2 is not a straight line but shows some decrease in the rate of production of the measured current at higher speeds. We believe that the total charge produced at the surface of the tire is directly proportional to speed at all the speeds indicated and that this falling off of current measured at high speeds is due to changes in the equivalent resistances, $R_{q}$ and $R_{v}$, shown in Figure 1 .

With increased speed it is to be expected that the tire temperature will increase. Rubber, as compounded and used in tires, has a negative temperatureresistance coefficient. Therefore, the tread and the surface of the tire near the tread, due to its higher temperature, will decrease in resistance more than the main body of the tires. Since most of $R_{0}$ resides in the tread and in the portions of the tire near the tread, $R_{0}$ decreases more than $R_{v}$ as the speed increases. A greater portion of the total current generated thus goes to ground through the shunt path, and the readings of the ammeter flatten out.

Figure 3 indicates that an increase in temperature will change the ratio of resistance $R_{w o}$ to $R_{g}$. This curve shows the current measured at a constant speed, plotted against time. Before this run, the tires were allowed to cool. There is a decrease in measured current for about a minute, and then a substantially constant value is reached. This manner of change of current measured is explained by assuming that the ratio of $R_{v}$ to $R_{v}$ decreases as the temperature of the tires increased. It is difficult to explain the observed change in current by anything other than the change of tire resistance with time.

The experiment that indicated the existence of two paths to ground, as illustrated in Figure 1, was the following: A conducting mixture of lampblack and Karo syrup was applied to the side walls of the tires. The conducting film extended from the metal wheel hub to within an inch of the outer edge of the side walls of the tires. The tread was not coated, so that the charge-producing mechanism was not affected, and the same total currents as previously produced would be generated at the tread of the tire. When the wheels were now set in motion, much higher currents to the car than previously encountered, were measured.

On the assumption that the total current generated at the tread of the tire is unchanged at a given speed, these results indicate that the total current must split into two paths, as shown in Figure 1, and that the ammeter reads only a portion of the total current generated.

Currents as high as eight microamperes at 40 miles per hour were obtained with a relatively thick coating of the conducting mixture. The resistance of the side walls was so decreased that two electrodes spaced three inches apart, indicated a resistance of approximately $100,000 \mathrm{ohms}$.

Furthermore, it is impossible to determine directly the total current generated at any particular speed. This can be seen if the circuit elements of Figure 1 are considered to constitute a $\Pi$ network. From four-terminal network theory, it is known that three independent measurements must be made to determine the characteristics of the circuit. This means that two measurements must be made on one side of the network and one on the other. This is physically impossible, because no meters can be connected to that side of the circuit where the constant current $I$ is being injected into the system.

However, if external resistances are inserted in series with the ammeter, and the current change measured, certain interesting results may be obtained. It is readily determined that

$\frac{1}{I_{u}}=\frac{1}{I}+\frac{R_{w}}{I R_{0}}+\frac{R_{e}}{I R_{g}}$, where $R_{e}$ is the unlabeled external resistance in Figure 1.

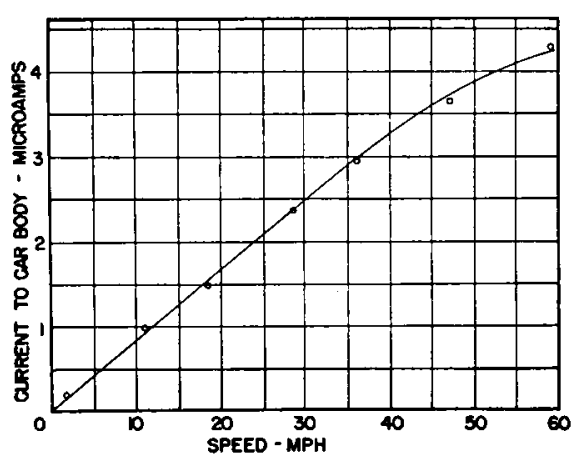

Figure 2. Typical curve of current measured from body of car to ground, as speed of rear wheels is changed
Thus, the reciprocal of the measured current for a given total current $I$, that is, for a constant speed, should vary linearly with the external resistance. The slope of the line is

slope $=1 / I R_{0}$

and the intercept is given by

intercept $=\frac{1}{I}\left(\frac{R_{o}+R_{w}}{R_{\vartheta}}\right)$

and therefore

$\frac{\text { intercept }}{\text { slope }}=R_{v}+R_{w}$

Figure 4 shows the results of readings taken at a wheel speed corresponding to 40 miles per hour. Extremely high resistances had to be added in the ammeter circuit to obtain these data. It is seen that a straight line, predicted by analyzing the equivalent circuit, is actually obtained. This curve gives a value of $R_{w}+R_{g}=1,325$ megohms. Further data, taken with the side walls made conducting, also yield a straight line; in this case, $R_{w}+R_{0}=34.6$ megohms.

Without a knowledge of the total current $I$, it is not possible to determine the exact value of $R_{p}$ and $R_{w}$. However, an idea of the order of magnitude can be determined in the following manner: as mentioned, with a relatively thick conducting layer, currents as high as eight microamperes at 40 miles per hour have been measured. We may assume that this is approximately the total current generated at this speed, since without any conducting layer, and with no external resistance, the measured current is 1.74 microamperes.

The slope of the curve of Figure 4 is $1 / I R_{g}=0.43 \times 10^{-3}$. Substituting the value of $I=8 \times 10^{-6}$, we get $R_{g}=290$ megohms. Since $R_{w}+R_{g}=$ 1,325 megohms, then $R_{w}=1,035 \mathrm{meg}$ ohms.

These results give the resistance of the two rear wheels in parallel. Consequently, the equivalent resistances for one tire would be $R_{\ell}=580$ megohms, and $R_{20}=2,0 \overline{0} 0$ megohms.

This determination of $R_{w}$ is in the range of the resistance between the hub of a wheel and a metal plate on which a tire is resting. The authors have made such measurements, ${ }^{4}$ as have Cadwell, Handel. and Benson. ${ }^{2}$

If we assume that the total current generated by the tires is proportional to speed, we obtain, on the assumptions previously stated, a "proportionality constant" of approximately 0.1 microampere per mile per hour for each tire.

It will be noted that the value shown on 
Figure 4 for the current measured at 40 miles per hour with $R_{e}=0$, is 1.7 microamperes, or approximately one half of the current for this speed shown on Figure 2. Such changes were encountered over a period of time, and were probably caused by changes in the surface conditions of the tires.

\section{Voltages Encountered}

The slope of Figure 4 is given by $1 / L R_{0}$. Accordingly, the reciprocal of the slope is the voltage to which the vehicle would be raised if all the current were dissipated to ground through the shunt resistance. This situation is approximated when extremely high external resistances, $R_{e}$, are used. For the data taken with the normal tire, this value is

\section{$V=(1 / 0.43) \times 10^{3}=2,320$ volts}

During these experiments voltages of this size were measured, and Beach ${ }^{1}$ likewise encountered voltages in this range, although somewhat higher. If an electrostatic voltmeter is applied to the car while on the dynamometer, instead of an ammeter, and one side of the voltmeter is grounded, then $R_{e}$ will be the resistance of the front tire and the surface leakage over the floor to ground.

We made tests in which a layer of tinfoil was placed under the front tires, the tinfoil being insulated from the floor by rubber mats. The tinfoil was then grounded through the microammeter. As soon as the rear wheels started to turn, the microammeter indicated a current of about half the size previously encountered and a voltmeter connected between the car body and ground read several thousand volts. This, as stated above, is equivalent to inserting a very high resistance $R_{e}$ in the ammeter circuit of Figure 1.

Those who previously made measurements of voltage, in attempting to analyze

Table I. Data Obtained on Road

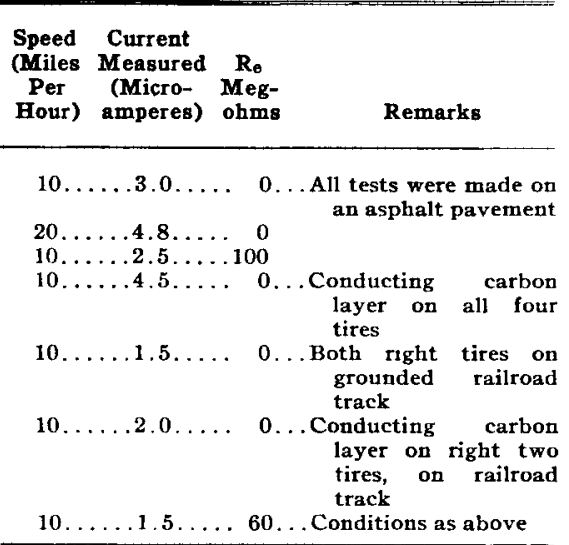

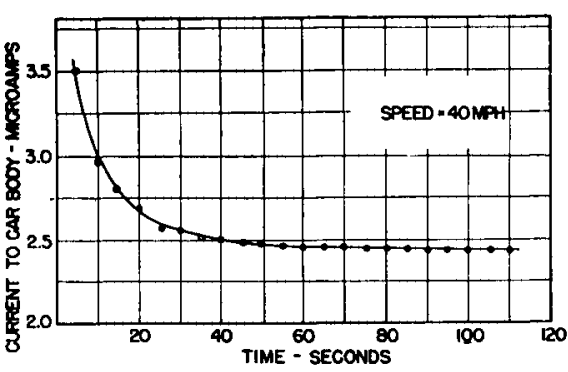

Figure 3. Variation of current to car body with time, wheel speed being held constant at $\mathbf{4 0}$ miles per hour

the problem of the tire static, were performing this experiment, without realizing that the voltages measured could be correlated directly with an $I R$ drop through the front tires.

\section{Road Tests}

Data were also taken with vehicles actually in motion. However, it was rather difficult to get good readings. First of all, other cars passing nearby would induce temporary currents of the

\section{Figure 5. Equivalent circuit of} a car moving on a highway
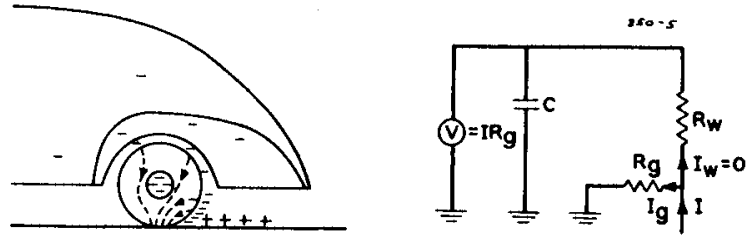

order of magnitude of those being measured. Mechanical meters, sensitive enough to read the current generated, were not rugged enough to stand the inevitable shocks received in a moving vehicle. Electronic meters were too susceptible to outside influence, such as power lines, and so forth. Despite this, the data obtained checked well with what might be anticipated from the dynamometer tests.

In the road tests, a chain about ten feet long was dragged in a railroad track, serving as a constant ground. The chain was insulated from the car by means of a wax-impregnated rope which also served as the strain absorber. The wire leading to the ammeter inside the car was insulated from the metal of the car by vacuum-held rubber cups. Accordingly, measurements could be made corresponding to $I_{w}$ of the dynamometer experiments.

The most reliable data for the operating conditions detailed are listed in Table I. It is seen from this table that the order of magnitude of currents generated is that obtained on the dynamometer. Closer correlation is scarcely to be expected. The materials producing the charges were different: that is, on the dynamometer the rubber contacted metal, while in

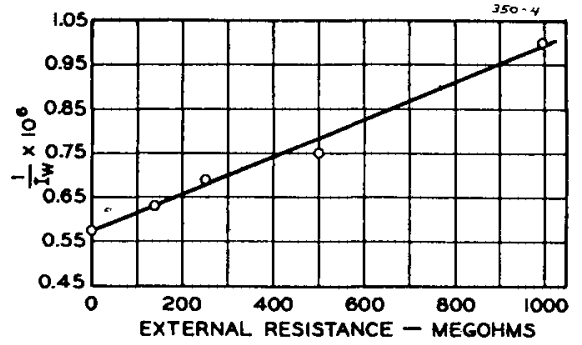

Figure 4. Reciprocal of current measured versus external resistance in ammeter circuit

Speed-40 miles per hour

these tests the rubber contacted asphalt paving.

We may see further, from the data taken with the right wheels in the grounded track, that reducing the value of the leakage resistance to ground will reduce considerably the amount of current going to the car. On the dynamometer stand, the path $R_{g}$, as mentioned previously, was the rubber between the charges and the grounded dynamometer, while on the road, the pavement resistance is added. Therefore, driving on the 
flow to the body of the car. Thus, the car does not charge up indefinitely; the voltage to which it will rise is given by $I R_{0}$.

In order to decrease the potential acquired by a vehicle in motion, two methods may be used:

1. To reduce the amount of total charge produced. A method of doing this has already been proposed. ${ }^{2}$

2. To use tires with conducting tread and side walls. This would reduce the resistance $R_{g}$ and, consequently, decrease the vehicle's potential.

Experience has shown that very seldom is a car sufficiently charged to give a static spark when driven into a service station. Even if we assume that a vehicle is brought to rest with a relatively high charge, this charge quickly leaks to ground. We have measured the resistance of the tires of a number of cars when at rest and found this resistance to be approximately $3 \times 10^{9} \mathrm{ohms}$ for four tires in parallel. ${ }^{3,4}$ The capacitance of a car is approximately 750 micromicrofarads. If we assume that a car is brought to rest with a potential of 3,000 volts, then we can make a rough calculation of the time required for the vehicle to discharge to 300 volts, which is the minimum sparking potential.

From the usual capacitor-resistance discharge equation

$V=V_{o} e^{-\frac{t}{R C}}$

Substituting $V=300, V_{o}=3,000 R=$ $3 \times 10^{9}, C=750 \times 10^{-12}$ we find $t=5.2$ seconds.

Furthermore, we have found in the laboratory that a capacitor of 750 micromicrofarads will produce a spark capable of igniting a combustible mixture of gasoline vapor and air, only if charged to a potential of several thousand volts. A spark may occur at a lower voltage, but it lacks the characteristics necessary to ignite a combustible mixture of gasoline vapor and air.

\section{References}

1. Static Electricity on Rubber-Tired VeHicles, R. Beach. Electrical ENGINRERING, volume 60, May 1941, pages 202-08.

2. Static Electrictiy and Its Effect on Car Radio Performance, S. M. Cadwell, N. E. Handel, G. L. Benson. News Edition, American Chemical Society, volume 19, October 25, 1941, pages $1139-41$.

3. Static Electric Problems in Tires, J. W. Liska, E. E. Hanson. Industrial and Engineering Chemistry, volume 34, May 1942, pages 618-24.

4. Electrical Charges produced by Flowing GaSoline, S. S. Mackeown, V. Wouk. Industrial and Enginecring Chemistry, volutne 34, June 1942, pages 659-64.

\title{
Pilot-Wire Circuits for Protective Relaying-Experience and Practice
}

\author{
AIEE COMMITTEE ON PROTECTIVE DEVICES \\ RELAY SUBCOMMITTEE
}

B

ECAUSE of the increasing use of pilot-wire relays, particularly for longer lines, the relay subcommittee initiated an investigation of the operating experience with the pilot channel itself. From this investigation it was hoped to determine the requirements for a reliable pilot channel. Unfortunately, the information obtained to date is not conclusive, and under war conditions the completion of this investigation appears
It should be remembered that the recent increased use of pilot-wire relay schemes has been occasioned by the development of new relays to give both phase and ground-fault protection over only two pilot wires. Because of the short history of these new developments, this report necessarily gives a rather incomplete picture of their performance, since it is influenced disproportionately by the much longer period of use of the

Table A

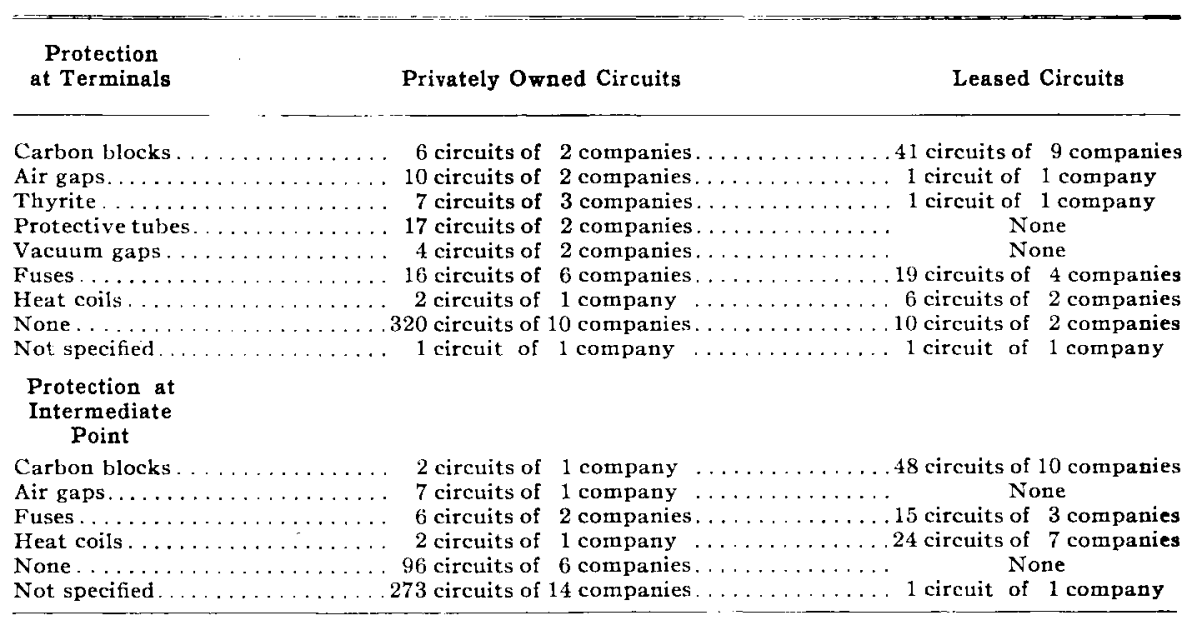

to be delayed unavoidably. On the other hand, plant expansion necessary to the war effort frequently has called for quick decisions on relay schemes, and pilot wires have been used in many cases. Because the pilot-wire channel is the least known item in the pilot-wire relay scheme, the committee has decided to publish the information now available to indicate the trend, so that prospective users of pilot-wire relaying may have the benefit of this preliminary work. Investigation will be continued as actively as conditions permit and another report issued as soon as sufficient data are available.

Paper 43-27, recommended by the AIEE committee on protective devices for presentation at the AIEF national technical meeting, New York, N. Y., January 25-29, 1943. Manuscript submitted November 12, 1942; made available for printing December 29, 1942 .

Personnel of the working group on pilot wires of the relay subcommittee: $W$. $K$. Sonnemann, sponsor; J. H. Neher, former sponsor (now with the United States Navy); J. C. Bowman, W. R. Brownlee, R. E. Cordray, R. F. Davis, I. I. Draper, E. E. George, S. Goldsmith, E. L. Harder, H. F Lindemuth, W. E. Marter, P. N. Sandstrom, A. W Walton, E. M. Wood older schemes. Further, it is probable that, in some of the cases where phase or ground-fault protection only is reported, the circuits would have been protected for both, had the newer schemes been available at the time. Also, the use of the newer schemes probably will increase the average length of pilot-wire circuits, because of their ability to operate over longer distances.

This report is based on the replies of 32 companies covering 436 circuits used for protective relaying. The information thus obtained covers 1,351 route miles of pilot-wire circuits and a period of 5,570 circuit years.

The following information, some of which is elaborated on later, would appear to be particularly significant.

1. Eighty-seven per cent of the circuits are privately owned, nearly all of which are in lead-sheathed cable. The average length is three miles. The longest circuit is 26 miles.

2. Two thirds of the circuits are installed on the same right of way or in the same duct 